\title{
It is Never Too Late to Start a New Life
}

I came to Scotland with the hope of securing a better life at the age of 14 years. I began gambling as a child, but became hooked when I started working at my parents' restaurant. I gambled for more than 30 years, dreaming about wealth and having face. I bet on horse racing, soccer matches, pokies, and casino games. At first, gambling was good fun and helped enhance social interactions with workmates and friends. Soon, I invested more time, money, and energy solely on gambling activities. I lost my sanity and selfcontrol. I completely neglected my job, my family, and my friends. My family was torn apart because we argued all the time. I frequently lied to hide my gambling involvement and gambling debts. I even gambled away the money that my wife had set aside for buying the plane tickets to visit my mother-in-law who was seriously ill in Hong Kong.

I tried to stop gambling, but it had never lasted long. I stole money from my brother and took money from my children shamelessly. My family wept and repaid my gambling debts again and again. I lost my cars, houses, property, and dignity. My wife wanted to divorce me, and asked me to leave. Having nowhere to go, I resorted to gambling at a casino for 3 days. I felt so depressed and guilty that I considered killing myself. Fortunately, my son called me, and asked my wife to give me one last chance. My wife agreed and brought me to the Christian Centre for Gambling Rehabilitation (CCGR) in London. We were impressed with the supervisor's empathetic understanding of our desperate situation. Peter Chan, who is Centre Manager of the CCGR, integrated spiritual healing and gambling counseling in his work. My wife and I came to Christ in our first visit to the Centre.

Miraculously both my gambling and smoking addictions disappeared at that time. I have not experienced any cravings for gambling or smoking for more than four years. I feel as if I have a new life! My faith has also renewed my values and changed my lifestyle. I gave up my dream of big winnings to boost self-worth and pride. I began enjoying going to the church and attending the Centre's group meetings. For three years, my wife has shown her unfailing support by accompanying me in almost all my visits to the church and the Centre's group meetings. We have made new friends and developed new leisure activities.

We treasure the group meetings most. With mutual support, we have shared our struggles and painful experiences. We have learnt from one another how to stay away from gambling temptations, and how to lead a better life. My family has forgiven me for my wrongdoings, and we have worked very hard to rebuild our family life together. This was the very first time that I experienced the preciousness of peace and happiness. 
Although I have lost all my fortune, I am glad that I have faith and a happy family. I enjoy my life serving at the church, and have been a co-worker at the CCGR since 2009. I am grateful for the help that I have received and now wish to serve others. My recovery experience shows that it is never too late to seek help and to turn a new page in your life!

Summarized by Peter Chan Christian Centre for Gambling Rehabilitation, London 